\title{
Bladder Cancer pTX TNM Finding v8
}

National Cancer Institute

\section{Source}

National Cancer Institute. Bladder Cancer PTX TNM Finding v8. NCI Thesaurus. Code C140393.

Bladder cancer in which the primary tumor cannot be assessed. (from AJCC 8th Ed.) 